\title{
REGIONAL RADIOCARBON EFFECT DUE TO THAWING OF FROZEN EARTH
}

\author{
P. E. DAMON, ${ }^{1}$ GEORGE BURR, ${ }^{2}$ A. N. PERISTYKH, ${ }^{3}$ G. C. JACOBY ${ }^{4}$ and R. D. D'ARRIGO
}

\begin{abstract}
Accelerator mass spectrometry (AMS) measurement of 25 single-year tree rings from AD 1861-1885 at ca. $\pm 3.5 \%$ precision shows no evidence of an anomalous 11 -yr cycle of ${ }^{14} \mathrm{C}$ near the Arctic Circle in the Mackenzie River area. However, the $\Delta^{14} \mathrm{C}$ measurements are lower on average by $2.7 \pm 0.9(\bar{\sigma}) \%_{0}$ relative to ${ }^{14} \mathrm{C}$ measurements on tree rings from the Pacific Northwest (Stuiver and Braziunas 1993). We attribute this depression of $\Delta^{14} \mathrm{C}$ to thawing of the ice and snow cover followed by melting of frozen earth that releases trapped ${ }^{14} \mathrm{C}$-depleted $\mathrm{CO}_{2}$ to the atmosphere during the short growing season from May through August. Correlation of $\Delta^{14} \mathrm{C}$ with May-August estimated temperatures yields a correlation index of $r=$ 0.60 . The reduction in $\Delta^{14} \mathrm{C}$ is dominated by seven years of anomalous depletion. These years are $1861,1867-1869,1879$ 1880 and 1883 . The years $1867-1869$ are coincident with a very strong ENSO event.
\end{abstract}

\section{INTRODUCTION}

This work is a continuation of a preliminary study of $\Delta^{14} \mathrm{C}$ variations in tree rings (Picea glauca, white spruce) from the Grand View site, Mackenzie River area of the Northwest Territories of Canada at $67^{\circ} \mathrm{N}, 130^{\circ} \mathrm{W}$ (Damon et al. 1992). The preliminary study was prompted by a report that $\Delta^{14} \mathrm{C}$ measurements on tree rings from that site "exhibit a $10 \%$ fluctuation with an 11 -yr periodicity anticorrelated with the solar activity cycle" (Fan et al. 1986: 300). Such a large variation in the 11-yr Schwabe cycle is not predicted from global carbon cycle models that yield a peak-to-trough variation of ca. 2\%o (e.g., Damon, Sternberg and Radnell 1983; Stuiver and Braziunas 1993). This large variation would require a highly significant regional effect and, consequently, demanded verification. Our preliminary study did not verify an anomalous variation in the $11-\mathrm{yr} \Delta \Delta^{14} \mathrm{C}$ cycle. However, both studies suggested a smaller regional effect involving significantly lower average $\Delta^{14} \mathrm{C}$ measurement of $2.6 \pm 0.9(\bar{\sigma}) \% o$ when compared to trees from the U.S. Pacific Northwest (Stuiver and Braziunas 1993). We suggested that this lowering could be caused by release of ${ }^{14} \mathrm{C}$-depleted $\mathrm{CO}_{2}$ from the continuous thawing of frozen earth during the relatively short growing season near the Arctic Circle. As pointed out in our preliminary paper, such effects are not unprecedented, and the effect observed for the Grand View site would require addition of only $5 \%{ }^{14} \mathrm{C}$-depleted $\mathrm{CO}_{2}$ to the prevailing air mass during the short growing season.

To further confirm this regional effect, we obtained additional measurements on previously measured samples and extended the measurements back to $A D 1861$, providing a set of $25 \Delta^{14} \mathrm{C}$ measurements.

\section{METHODS}

The methodology is essentially the same as in the preliminary paper (Damon et al. 1992) except for the introduction of a 32-position carousel to the accelerator mass spectrometer. Eight positions are occupied by 4 each of NIST Oxalic Acid I and II (HOxI and HOxII). Typically two blanks are included, leaving 22 positions for samples to be measured.

The analysis provides the measured ratios, ${ }^{14} \mathrm{C} /{ }^{13} \mathrm{C}$ for the samples and standards. The ratios are corrected for isotope fractionation. It is customary to normalize the standards to the year $1950 \mathrm{AD}$, corrected to remove the Suess effect (which is dominated by a decrease in the atmospheric isotopic ${ }^{14} \mathrm{C}$

\footnotetext{
${ }^{1}$ NSF-Arizona AMS Facility, Department of Geosciences, The University of Arizona, Tucson, Arizona 85721 USA ${ }^{2}$ NSF-Arizona AMS Facility, Department of Physics, The University of Arizona, Tucson, Arizona 85721 USA ${ }^{3}$ Department of Geosciences, The University of Arizona, Tucson, Arizona 85721 USA

${ }^{4}$ Tree-Ring Laboratory, Lamont-Doherty Earth Observatory of Columbia University, Palisades, New York 10964 USA
} 
concentration due to the combustion of fossil fuels, but also includes the lesser effects of a decreasing magnetic field and increasing solar activity). The normalization factors when measuring ${ }^{14} \mathrm{C} /{ }^{13} \mathrm{C}$ ratios are as follows (Donahue, Linick and Jull 1990):

$$
(14 / 13)_{1950[-25]}=0.9558(14 / 13)_{\text {HOxI[-19] }}=0.7404(14 / 13)_{\text {HOxII[-17.8] }}
$$

where the isotopic composition of HOxI relative to the PDB stable carbon isotope standard is $-19 \%$ and for HOxII, $-17.8 \%$. From the corrected ratios, a fraction modern is obtained, defined as

$$
F=\frac{\left({ }^{14} \mathrm{C} /{ }^{13} \mathrm{C}\right)_{\text {sample }}}{\left({ }^{14} \mathrm{C} /{ }^{13} \mathrm{C}\right)_{\mathrm{STD}}}
$$

The quantity $F$ is then used to calculate $\Delta^{14} \mathrm{C}$ in Equation 3

$$
\Delta^{14} \mathrm{C}=\left[\left(F \mathrm{e}^{\lambda(1950-\tau)}-1\right) 1000\right.
$$

where $\tau$ is the sample age measured in calendar years and $\lambda$ is based on the 5730 -yr half life $(\lambda=1$ / $8270 \mathrm{yr}^{-1}$ ). The normalization in Equation (1) is such that $\Delta^{14} \mathrm{C}$ passes through zero in the mid-19th century prior to the Suess effect.

May through August temperatures were estimated using tree-ring density data measured by X-ray and image analysis (Thetford, D'Arrigo and Jacoby 1991).

\section{RESULTS AND DISCUSSION}

The Mackenzie River data are presented in Table 1 and are plotted along with the Pacific Northwest data of Stuiver and Braziunas (1993) in Figure 1. Data from the Grand View site are lower than the data from the Pacific Northwest by $-2.7 \pm 0.9(\bar{\sigma}) \%$. However, the difference would not be significant if $7 \mathrm{yr}$ of the 25 -yr sequence less than $-10.0 \%$ were eliminated from the comparison (1861, $1867-1869,1879-1880$ and 1883). The remaining 18 results would differ from the Pacific Northwest data by only $-0.4 \pm 0.7(\bar{\sigma}) \%$. This is excellent but fortuitous agreement because the two sites are not environmentally equivalent. In evaluating this $-2.7 \%$ average depression of $\Delta^{14} \mathrm{C}$ at the Grand View site relative to the Pacific Northwest, it should be recalled that there is evidence for a marine west coast USA regional effect involving an average depression of $c a$. $-4 \%$ relative to Irish oak or Douglas-fir from the Santa Catalina Mountains near Tucson (Damon 1995; McCormac et al. 1995). This has been attributed to the upwelling of ${ }^{14} \mathrm{C}$-depleted $\mathrm{CO}_{2}$ along the Pacific west coast. This implies a Grand View site average depression relative to the Irish and Santa Catalina sites of $\mathrm{ca}$. $-6.7 \%(c a .56 \mathrm{yr})$. Even if we eliminate the 7 most negative $\Delta^{14} \mathrm{C}$ values from the Grand View site, agreement of the remaining 18 with the Pacific Northwest implies that both sites are depleted with respect to the Irish and Santa Catalina sites. However, there appears to be secular variation in depletion for both the Grand View site and the Pacific Northwest. In the earlier paper (Damon et al. 1992), we suggested that this relative depression could be the result of the thawing of frozen earth, releasing ${ }^{14} \mathrm{C}$-depleted $\mathrm{CO}_{2}$ during the short growing season (May-August). The extent of thawing would depend on temperatures during the growing season, with variance from season to season resulting in more or less depletion.

If this hypothesis is valid, there should be a relation between $\Delta^{14} \mathrm{C}$ and prevailing temperatures during the growing season in the Mackenzie region. High average May through August temperatures would result in deeper melting of frozen earth with continuous release of ${ }^{14} \mathrm{C}$-depleted $\mathrm{CO}_{2}$, and, presumably, the deeper the melt zone, the more ${ }^{14} \mathrm{C}$-depleted the released $\mathrm{CO}_{2}$. Figure 1 shows a plot 
TABLE 1. Analytic Data for Cellulose from Annual Tree Rings from the Grand View Site, NWT $\left(67^{\circ} \mathrm{N}, 130^{\circ} \mathrm{W}\right)$

\begin{tabular}{cccccc}
\hline $\begin{array}{l}\text { Date } \\
(\mathrm{AD})\end{array}$ & $\mathrm{F}_{\mathrm{m}}{ }^{*}$ & $\mathrm{~N}$ & $\begin{array}{c}\Delta^{14} \mathrm{C} \\
(\%)\end{array}$ & $\begin{array}{c} \pm \bar{\sigma} \\
(\%)\end{array}$ & $\begin{array}{c}\delta^{13} \mathrm{C} \\
(\%)\end{array}$ \\
\hline 1861 & 0.9775 & 3 & -11.9 & 3.7 & -23.2 \\
1862 & 0.9845 & 3 & -5.0 & 3.6 & -24.2 \\
1863 & 0.9870 & 3 & -5.1 & 3.7 & -23.0 \\
1864 & 0.9837 & 3 & -6.0 & 3.8 & -24.7 \\
1865 & 0.9908 & 3 & 1.0 & 3.5 & -23.4 \\
1866 & 0.9833 & 3 & -6.7 & 3.4 & -23.9 \\
1867 & 0.9788 & 3 & -11.3 & 3.5 & -23.0 \\
1868 & 0.9705 & 3 & -19.8 & 3.4 & -24.3 \\
1869 & 0.9768 & 3 & -13.6 & 3.3 & -23.8 \\
1870 & 0.9882 & 8 & -2.2 & 2.2 & -22.8 \\
1871 & 0.9833 & 7 & -7.3 & 2.3 & -25.2 \\
1872 & 0.9866 & 9 & -4.0 & 2.1 & -23.5 \\
1873 & 0.9844 & 9 & -6.4 & 2.1 & -23.5 \\
1874 & 0.9818 & 4 & -9.1 & 3.2 & $-22.7 \dagger$ \\
1875 & 0.9818 & 5 & -9.3 & 3.4 & $-22.7 \dagger$ \\
1876 & 0.9853 & 5 & -5.8 & 2.7 & -23.1 \\
1877 & 0.9828 & 4 & -8.5 & 7.5 & $-22.7 \dagger$ \\
1878 & 0.9888 & 5 & -2.6 & 3.4 & -21.8 \\
1879 & 0.9813 & 5 & -10.2 & 2.8 & $-22.7 \dagger$ \\
1880 & 0.9794 & 4 & -12.3 & 3.5 & $-22.7 \dagger$ \\
1881 & 0.9854 & 4 & -4.4 & 3.6 & -23.1 \\
1882 & 0.9866 & 4 & -5.3 & 3.2 & $-22.7 \dagger$ \\
1883 & 0.9810 & 3 & -11.0 & 3.4 & $-22.7 \dagger$ \\
1884 & 0.9897 & 4 & -2.4 & 2.7 & -23.3 \\
1885 & 0.9892 & 5 & -3.0 & 2.7 & $-22.7 \dagger$ \\
\hline
\end{tabular}

${ }^{*} \mathrm{~F}_{\mathrm{m}}=$ weighted average of $\mathrm{N}$ analyses

†Average of 7 analyses

of May-August temperatures (inverted scale) for a site in the Franklin Mountains near the Grand View site compared with the $\Delta^{14} \mathrm{C}$ from the Grand View site. Visual inspection suggests that a correlation may exist. Figure 2 presents a plot of $\Delta^{14} \mathrm{C} v s$. May-August average temperature. The quadratic polynomial curve fitted by minimum least squares deviation provides a reasonable fit to the data as shown. Only 5 of the 25 samples lie outside of 1 s.d. from the curve. The year 1868 plots at $3 \sigma$ from the curve but appears to be the culmination of the most intense negative fluctuation of $\Delta^{14} \mathrm{C}$ from 1867-1869 (Fig. 1), which is accompanied by a maximum of temperatures (Fig. 1). It is interesting that the years $1867-1869$ exactly coincide with a very strong ENSO event (Quinn 1992). The correlation index for the curve in Figure 2 is 0.60 , indicating that $36 \%$ of the variation can be explained by the dependence of $\Delta^{14} \mathrm{C}$ on May-August temperatures, where at first there is little dependence of $\Delta^{14} \mathrm{C}$ on temperatures and then a significant decrease of $\Delta^{14} \mathrm{C}$ when the growing season temperature exceeds $11.5^{\circ} \mathrm{C}$. The scatter about the quadratic polynomial curve in Figure 2 is compatible with the $\Delta^{14} \mathrm{C}$ measurement errors. However, because $11.5^{\circ} \mathrm{C}$ appears to be a threshold below which $\Delta^{14} \mathrm{C}$ is independent of temperature, an equally good fit could be obtained with two straight lines. 


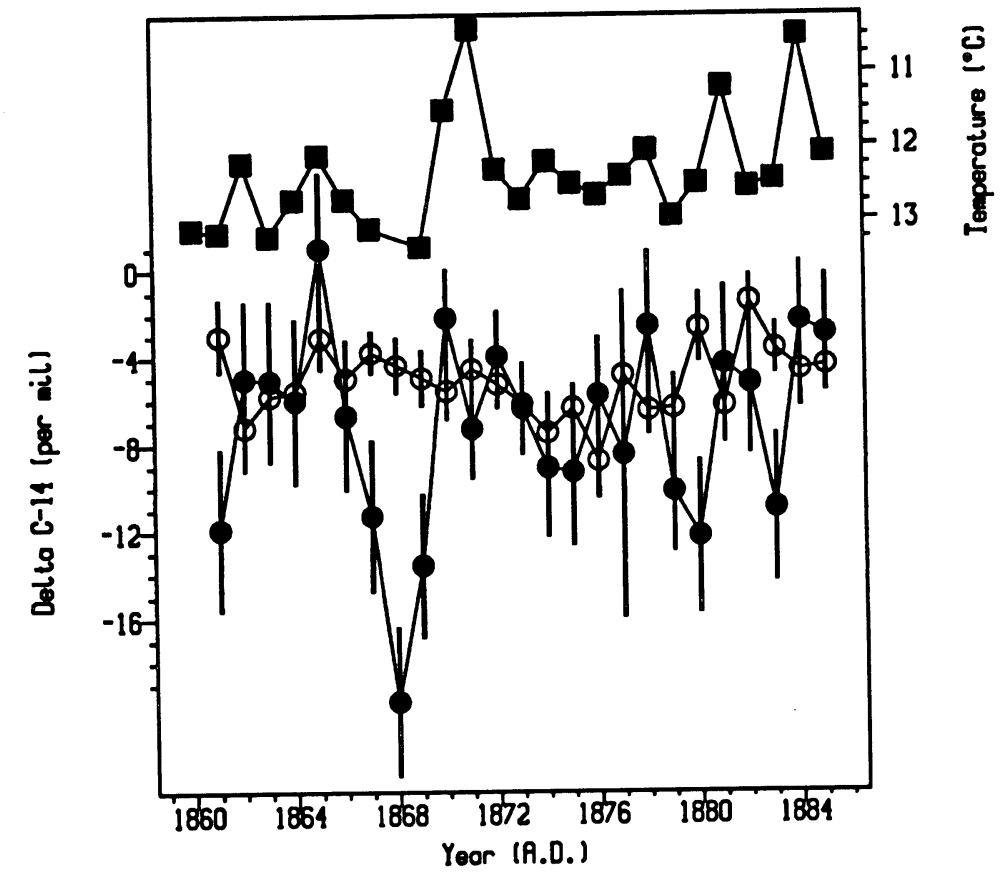

Fig. 1. $\Delta^{14} \mathrm{C}$ from two locations for the interval AD 1861 to $\mathrm{AD} 1885 . \bullet=$ data from Table 1 (Grand View site); $O=$ data from the Pacific Northwest, USA (Stuiver and Braziunas 1993). = estimated May through August temperatures determined densitometrically for trees from a nearby site.

\section{CONCLUSION}

The following conclusions seem to be warranted by the data:

1. There is no evidence for an anomalously intense 11-yr cycle at high latitudes in the Mackenzie River area during the time period AD 1861-1885.

2. There is an average difference of $-2.7 \pm 0.9(\bar{\sigma}) \% 0$ between $\Delta^{14} \mathrm{C}$ values for tree rings from the Pacific Northwest, USA compared with tree rings from the Grand View site near the Arctic Circle, N.W.T., Canada. However, this difference is dominated by seven years: $1861,1867-1869$, $1879-1880$ and 1883 . The years $1867-1869$ coincide exactly with a very strong ENSO event.

3. The correlation index for a quadratic polynomial fit to $\Delta^{14} \mathrm{C} v s$. May through August temperatures in that area is $r=0.60$, suggesting that $36 \%$ of the variance is related to temperature. Measurement errors are compatible with the scatter about the quadratic polynomial curve.

4. The -2.7\%o depletion of $\Delta^{14} \mathrm{C}$ in tree rings from the Grand View area corresponds to a ca. 22 yr older apparent age when compared to tree rings from the Pacific Northwest, USA. On the other hand, Douglas-fir from the Santa Catalina Mountains near Tucson and Irish oak (Damon 1995; McCormac et al. 1995) would yield apparent ages ca. $33 \mathrm{yr}(+4 \% 0)$ younger than tree rings from the Pacific Northwest. We conclude from this that regional effects are not negligible, even within the northern hemisphere, and must be taken into consideration in the calibration of ${ }^{14} \mathrm{C}$ dates. 


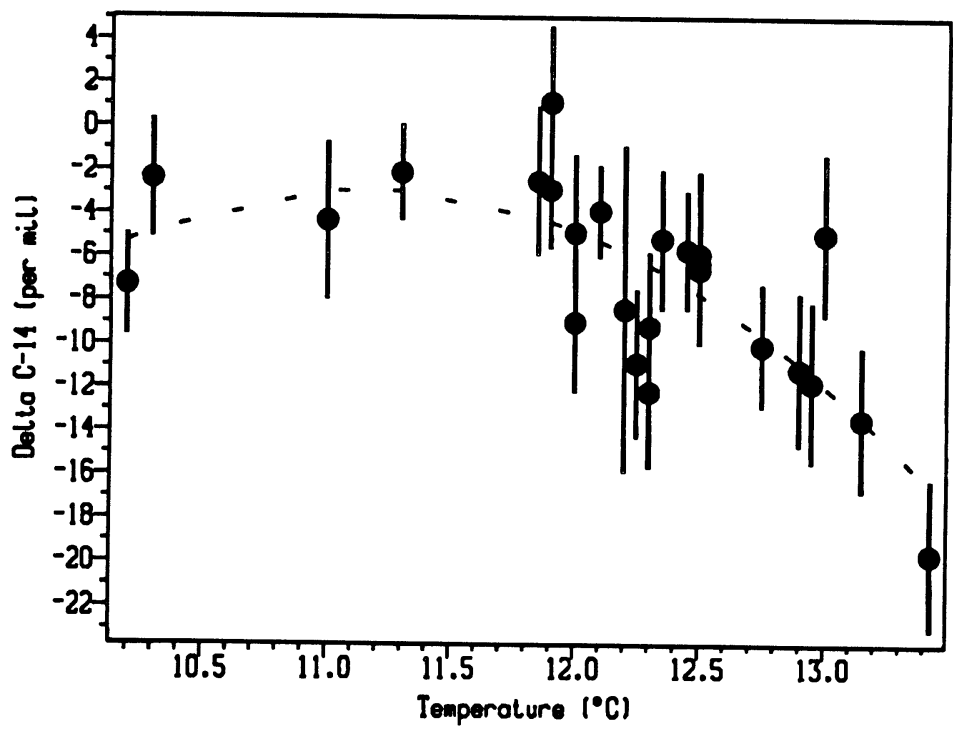

Fig. 2. $\Delta^{14} \mathrm{C}$ vs. May through August estimated temperatures. With no points eliminated, the correlation index $r=0.60$ suggests that the $\mathrm{T}-\Delta^{14} \mathrm{C}$ relationship explains $36 \%$ of the variance. Eliminating the one anomalous point increases the correlation to $41 \%$. The scatter about the quadratic polynomial reference line is explainable by the $\Delta^{14} \mathrm{C}$ measurement errors. There is little variation below $11.5^{\circ} \mathrm{C}$, which appears to be a threshold. Hence, the curve could be replaced by two straight lines as an equally good fit.

A negative $\Delta^{14} \mathrm{C}$ for tree rings from the Grand View area implies the addition of ${ }^{14} \mathrm{C}$-depleted $\mathrm{CO}_{2}$ into the prevailing atmosphere accessible to the trees during the growing season in that area. The most likely source of ${ }^{14} \mathrm{C}$-depleted $\mathrm{CO}_{2}$ is its release during the thawing of ice, snow and frozen earth. We documented the existence of a similar effect for radon in a previous paper (Damon et al. 1992). A study of $\mathrm{CO}_{2}$ in soil gas above the water table from the western Great Plains of the United States has shown that $\mathrm{CO}_{2}$ and ${ }^{14} \mathrm{CO}_{2}$ are biologically generated, with partial pressures 1-2 orders of magnitude greater than those in the atmosphere (Haas et al. 1983; Thorstenson et al. 1983). Hence, the diffusion gradient of $\mathrm{CO}_{2}$ is toward the surface and, as a consequence, surface $\Delta^{14} \mathrm{C}$ is depleted by as much as $23 \%$ relative to the open atmosphere. $\Delta^{14} \mathrm{C}$ decreased with depth until the water table was reached. The ${ }^{14} \mathrm{C}$ concentration at depth but above the water table reduced to as little as a few percent modern. If, as seems likely, a similar $\Delta{ }^{14} \mathrm{C}$ gradient exists at the Grand View site, ${ }^{14} \mathrm{C}$-depleted $\mathrm{CO}_{2}$, like radon, would be trapped below the ice and snow cover during the long season of freezing temperatures until it is released during the thaw in late spring. Subsequently, melting of frozen earth would release more ${ }^{14} \mathrm{C}$-depleted $\mathrm{CO}_{2}$; the deeper the melting, the more ${ }^{14} \mathrm{C}$-depleted the $\mathrm{CO}_{2}$. Therefore, there would be a tendency toward lower $\Delta{ }^{14} \mathrm{C}$ values in seasons with warmer May through August temperatures, as shown in Figure 2. For example, let us assume that the trapped $\mathrm{CO}_{2}$ is $25 \%$ depleted and has the same $\delta^{13} \mathrm{C}$ as the average in Table $1(-23.5 \%)$. If the atmosphere at tree level contains $5 \%$ of the released soil gas, it would be depleted in ${ }^{14} \mathrm{C}$ by $-11.5 \%$ and its $\delta^{13} \mathrm{C}$ would be $-7.8 \%$. The $-0.8 \%$ shift in $\delta^{13} \mathrm{C}$ is small compared to the spread of $\delta^{13} \mathrm{C}$ values in Table 1 of 3.4\%o. Thus, variation other than the admixing of soil gas dominates the $\delta^{13} \mathrm{C}$ measurements, considering that measured precision is $< \pm 0.1 \%$. 


\section{ACKNOWLEDGMENTS}

The tree-ring samples from the Grand View site were collected and analyzed by Drs. Gordon Jacoby and Rosanne D'Arrigo of the Tree-Ring Laboratory, Lamont-Doherty Earth Observatory. Their work was supported by NSF grant ATM 9406732. Dr. Ramzi Touchan supervised preparation of single-year tree rings. Cellulose was prepared under the supervision of Dr. Christopher Eastoe, Department of Geosciences, The University of Arizona. We thank members of the NSF-Arizona Accelerator Laboratory for radioisotope analysis, particularly Larry Toolin and Dana Biddulph for assistance in preparing graphite targets. We thank Dr. Austin Long for his careful reading and helpful suggestions, and Dr. Warren Beck for pointing out the coincidence of the $1867-1869 \Delta^{14} \mathrm{C}$ anomaly with a very strong ENSO event during those years. Investigations at the University of Arizona were supported by NSF grants EAR-9508413 and ATM-9520135 and the State of Arizona.

\section{REFERENCES}

Damon, P. E. 1995 A note concerning "Location-dependent differences in the ${ }^{14} \mathrm{C}$ content of wood" by McCormac et al. In Cook, G. T., Harkness, D. H., Miller, B. F. and Scott, E. M., eds., Proceedings of the 15th International ${ }^{14} \mathrm{C}$ Conference. Radiocarbon 37(2): 829830.

Damon, P. E., Burr, G., Cain, W. J. and Donahue, D. J. 1992 Anomalous 11-year cycle at high latitudes? Radiocarbon 34(2): 235-238.

Damon, P. E., Sternberg, R. S. and Radnell, C. J. 1983 Modeling of atmospheric radiocarbon fluctuations for the past three centuries. In Stuiver, M. and Kra, R., eds., Proceedings of the 11 th International ${ }^{14} \mathrm{C}$ Conference. Radiocarbon 25(2): 249-258.

Donahue, D. J., Linick, T. W. and Jull, A. J. T. 1990 Isotope-ratio and background corrections for accelerator mass spectrometry radiocarbon measurements. $R a$ diocarbon 32(2): 135-142.

Fan, C. Y., Chen, T. M., Yun, S. X. and Dai, K. M. 1983 Radiocarbon activity variation in dated tree rings grown in Mackenzie Delta. In Stuiver, M. and Kra, R., eds., Proceedings of the 12 th International ${ }^{14} \mathrm{C}$ Conference. Radiocarbon 28(2A): 300-305.

Haas, H., Fisher, D. W., Thorstenson, D. C. and Weeks, E. P. $1983{ }^{13} \mathrm{CO}_{2}$ and ${ }^{14} \mathrm{CO}_{2}$ measurements on soil atmosphere sampled in the sub-surface unsaturated zone in the western Great Plains of the US. In Stuiver, M.

and Kra, R., eds., Proceedings of the 11th International ${ }^{14} \mathrm{C}$ Conference. Radiocarbon 25(2): 301-314.

McCormac, F. G., Baillie, M. G. L., Pilcher, J. R. and Kalin, R. M. 1995 Location-dependent differences in the ${ }^{14} \mathrm{C}$ content of wood. In Cook, G. T., Harkness, D. H., Miller, B. F. and Scott, E. M., eds., Proceedings of the 15th International ${ }^{14} \mathrm{C}$ Conference. Radiocarbon 37 (2): 395-407.

Quinn, W. F. 1992 A study of southern oscillation-related climatic activity for A.D. 622-1900 incorporating Nile River flood data. In Diaz, H. F. and Markgraf, V., eds., El Niño: Historical and Paleoclimatic Aspects of the Southern Oscillation. Cambridge, Cambridge University Press: 119-150.

Stuiver, M. and Braziunas, T. F. 1993 Sun, ocean, climate and atmospheric ${ }^{14} \mathrm{CO}_{2}$ : An evaluation of causal and spectral relationships. Holocene 3(4): 289-305.

Thetford, R. D., D'Arrigo, R. D. and Jacoby, G. C. 1991 An image analysis system for generating densitometric and ring width time series. Canadian Journal of Forest Research 21: 1544-1548.

Thorstenson, D. C., Weeks, E. P., Haas, H. and Fisher, D. W. 1983 Distribution of gaseous ${ }^{12} \mathrm{CO}_{2},{ }^{13} \mathrm{CO}_{2}$, and ${ }^{14} \mathrm{CO}_{2}$ in the sub-soil unsaturated zone of the western US Great Plains. In Stuiver, M. and Kra, R., eds., Proceedings of the 11 th International ${ }^{14} \mathrm{C}$ Conference. $\mathrm{Ra}$ diocarbon 25(2): 315-346. 